\title{
Effect of micro-climate variations on carbonation rate of concrete in the inland environment
}

\author{
Yunusa Aminu Alhassan ${ }^{1}$, and Sunday Apeh $^{2}$ \\ ${ }^{1,2}$ Department of Civil Engineering, The Federal Polytechnic Idah, Nigeria
}

\begin{abstract}
In an inland environment, carbonation is the primary cause of initiation for potential corrosion of steel in reinforced concrete. This problem has been exacerbated over recent years by increased urbanisation and vehicular traffic, resulting in higher atmospheric carbon dioxide contents - a problem typical of economically active cities throughout the world. It is important that designers of reinforced concrete structures respond to these variations through appropriate specifications to ensure that structures perform satisfactorily over their intended service lives. This paper is part of a study undertaken to assess the carbonation of concretes exposed to a range of micro-climate variations in inland environments, particularly with variations in carbon dioxide content, temperature and relative humidity conditions with the intent of developing a prediction model for the rate of carbonation. Concretes samples were prepared using three binder types representing variations of blends with FA, GGBS and four w/b ratios ranging from 0.4 to 0.75 and subjected to different degrees of initial water curing $(3,7,28$ days). These samples were placed in three exposure conditions: indoors in laboratory air, outdoors sheltered from rain and sun and outdoors fully exposed to the elements. The depths of carbonation of these samples were monitored over a period of 24 months in order to determine the rates of carbonation. Concrete samples in the outdoor sheltered sites presented the highest rate of carbonation. Although samples in this exposure site carbonated faster, the risk of reinforcement corrosion is likely to be low because the samples are protected from direct moisture effect. Keywords: Carbonation, Corrosion, Reinforced concrete, Micro climate, Inland environments
\end{abstract}

\section{Introduction}

The major cause of deterioration in reinforced concrete is the corrosion of the steel reinforcement. The steel is susceptible to corrosion in the presence of chloride ions or if it becomes depassivated when the alkalinity of the concrete at the location of steel is reduced by carbonation. Carbonation is a chemical reaction between carbon dioxide, in the presence of moisture, and calcium hydroxide. The ability of concrete carbonization resistance is a very important index of durability [1]. The durability of reinforced concrete structures is mainly embodied in concrete cover to reinforcement. Corrosion of reinforcement caused by concrete carbonization is complicated. If measures are not taken, the time relative to the whole service life from reinforcement corrosion to structural failure is short. As a result, the service life of reinforced concrete can be shown by the ability of concrete carbonization resistance $[2,3]$.

Many researchers have shown that the concrete carbonization reaction depends on a number of factors. One is the quality of concrete, such as the intercommunicating pore structure and $\mathrm{Ca}(\mathrm{OH})_{2}$ content of concrete, the former determines the diffusion speed of $\mathrm{CO}_{2}$ in the concrete $[4,5]$. The latter is related to the ability of concrete absorbing $\mathrm{CO}_{2}$. Another very important aspect is the environmental conditions, such as temperature, humidity, $\mathrm{CO}_{2}$ concentration, etc. [6]. The diffusion ability of $\mathrm{CO}_{2}$ in concrete is partly dependent on the quality of concrete, including pore structure and moisture state, etc. At the same time, the ability of absorbing $\mathrm{CO}_{2}$ during the concrete carbonization process is mainly dependent on the type and content of cement.

Zhang and Jiang [7] considered the influence of the environmental relative humidity, the concentration of $\mathrm{CO}_{2}$, concrete water-binder ratio and cement content on carbonization and put forward a carbonization prediction model. The model proposed by Niu et al [8] considered the environmental temperature, humidity, the concentration of $\mathrm{CO}_{2}$ and the influence of the quality of concrete itself. Since the 1970s, the use of by-products like fly ash, ground granulated blast-furnace slag (GGBS) [9], silica fume (SF), rice husk ash, and metakaolin in cement and concrete production has gained rapid development $[10,11]$. The incorporation of these mineral admixtures in concrete has been of great interest and is gradually being applied to practical projects, because it could not only reduce concrete production cost, conserve energy and resources, reduce environmental pollution impact $[9,12]$, but also improve resistance to the deterioration of aggressive chemicals and permeation of aggressive materials [13, 14].

Generally, it is agreed that carbonation does not occur in the same way in all mixes, nor does it occur in all circumstances. Different mixes will exhibit distinct carbonation and the same mix exposed to different 
environments will not show the same carbonation. Hence, this study's main objective is to try to understand the conditioning factors so as to explain concrete carbonation. The author's intent is to develop knowledge of the rate of carbonation in the inland environment at the microclimate level, that will enable the reliable prediction of potential corrosion and hence the service life of reinforced concrete structures.

\section{Experimental Programme}

\subsection{Materials and mix proportion}

Three types of common cements were used in concrete mixtures prepared under the investigation. Ordinary Portland cement (OPC) of class CEM I 42.5 with or without $30 \%$ fly ash (FA) or $50 \%$ ground granulated blast-furnace slag (GGBS) was used. Since the type and proportions of supplementary cementing materials (SCMs) play a significant role in carbonation behavior of cementitious systems, it is important that the class of cement type used in concrete is known. Since the SCMs were incorporated by blending with CEM I, an equivalent standard cement class has been identified for each of the blended cement types used in mixtures, as given in Table 1. It can be seen that nearly all standard cement types typically used in structural concretes are represented in the investigation. Fine aggregate (quarry sand) and coarse aggregate (uncrushed gravel) of $19 \mathrm{~mm}$ nominal size were used. The fine aggregate was of medium grading in accordance with BS 882:1992.

Table 1. Cement types used in concrete mixes

\begin{tabular}{|l|l|l|l|}
\hline Cement type used & CEM I & $30 \%$ FA & 50\%GGBS \\
\hline $\begin{array}{l}\text { Equivalent standard } \\
\text { cement (EN 197-1, } \\
\text { 2000) }\end{array}$ & CEM I & CEM & CEM III/A, \\
& & II/B, & CEM IV/B \\
IV/A & \\
\hline
\end{tabular}

The concrete mixtures consisted of water-binder (w/b) ratios $=0.4,0.5,0.6,0.75$ and binder contents $=300$, $350,400,450 \mathrm{~kg} / \mathrm{m}^{3}$ made using a $19 \mathrm{~mm}$ granite coarse aggregate and granite crusher sand of standard gradation [15]. A commercially available plasticizer, Chryso Plast 90 was added in concrete mixes of 0.4 and $0.5 \mathrm{w} / \mathrm{b}$, to achieve slumps between 40 and $95 \mathrm{~mm}$. All the other mixtures had slumps ranging from 80 to $140 \mathrm{~mm}$, without use of the plasticizer. Table 2 gives details of the mixtures used in the investigation.

\subsection{Sample preparation and testing}

Concrete $100 \mathrm{~mm}$ cubes were cast using the mixtures in Table 2 for carbonation measurements. All the samples were cast and compacted in accordance with BS EN 12390-1 (2000). After casting, the samples were covered under damp hessian and polyethylene sheets for 24 hour. The samples were demoulded the following day and then immediately kept in a mist room at $20 \pm 2{ }^{\circ} \mathrm{C}$ and $98 \pm$ $2 \% \mathrm{RH}$ prior to exposure. In the investigation, the cube samples were exposed at outdoor sites to undergo carbonation under natural climate. The outdoor exposure environments were three different urban sites consisting of: the rooftop of a one storey building, samples stored at this location are considered not sheltered; the parking garage of a three storey building, samples exposed under this condition may be regarded as indoor; and beneath a foot bridge spanning over a busy highway, samples under this condition would be considered sheltered from sun and rain.

Prior to exposure of samples to the designated sites, cubes were removed from curing baths at ages of 3, 7, 28 days and air-dried under laboratory conditions for 14 days. All four sides running from the finishing surface through to its opposite end surface, were coated with two layers of epoxy coating, leaving the two adjacent opposite sides uncoated. A water-based epoxy obtained from StonCore Africa, was used. After sufficient drying of surface coatings over a 24 hour period, samples were taken to their respective exposure sites and placed at a spacing of at least $50 \mathrm{~mm}$ from each other such that the two non-coated surfaces were exposed to air. For each mixture, a set of four cubes, each set having been cured for 3, 7 or 28 days, was exposed at each of the three sites. At each exposure site, environmental factors were monitored using a 24-hour, automated data logger set up to record the micro-climatic conditions. The relative humidity $(\mathrm{RH}), \mathrm{CO}_{2}$ concentration and temperature were monitored for one year during the period under study. Data was recorded every minute and downloaded monthly into a computer hard-drive.

Carbonation measurements were carried out for concrete cubes of $100 \mathrm{~mm}$ biannually for 2 years of exposure in a varying micro-climatic condition. The samples were broken into two halves at six months interval. After splitting the concrete sample, the freshly split surface was cleaned and sprayed with a phenolphthalein $\mathrm{pH}$ indicator. The indicator used was a phenolphthalein $1 \%$ ethanol solution with $1 \mathrm{~g}$ phenolphthalein and $90 \mathrm{ml} 95.0 \mathrm{~V} / \mathrm{V} \%$ ethanol diluted in water to $100 \mathrm{ml}$. In the non-carbonated part of the sample, where the concrete was still highly alkaline, a purple-red colour was obtained. In the carbonated part of the sample where the alkalinity of concrete is reduced, no coloration occurred. The average depth of the colourless region was measured from three points, perpendicular to the two edges of the split face, both immediately after spraying the indicator and at 24 hour later. 
Table 2. Concrete mixtures used in the investigation

\begin{tabular}{|c|c|c|c|c|c|c|c|c|c|c|}
\hline \multirow{2}{*}{$\begin{array}{l}\text { Cement } \\
\text { type }\end{array}$} & \multirow{2}{*}{$\begin{array}{l}\text { Mix } \\
\text { No. }\end{array}$} & \multicolumn{3}{|l|}{$\begin{array}{l}\text { Binders } \\
\left(\mathrm{kg} / \mathrm{m}^{3}\right)\end{array}$} & \multicolumn{2}{|c|}{$\begin{array}{l}\text { Aggregate } \\
\left(\mathrm{kg} / \mathrm{m}^{3}\right)\end{array}$} & \multirow[t]{2}{*}{$\begin{array}{l}\mathrm{WC} \\
\left(\mathrm{kg} / \mathrm{m}^{3}\right)\end{array}$} & \multirow[t]{2}{*}{$\mathrm{w} / \mathrm{b}$} & \multirow[t]{2}{*}{$\begin{array}{l}\text { SP } \\
\text { (1) }\end{array}$} & \multirow[t]{2}{*}{$\begin{array}{l}\text { Slump } \\
(\mathrm{mm})\end{array}$} \\
\hline & & CEM I & FA & GGBS & $\mathrm{CA}$ & SA & & & & \\
\hline \multirow{4}{*}{ CEM I } & PC-40 & 450 & - & - & 990 & 800 & 180 & 0.4 & 4.00 & 45 \\
\hline & PC-50 & 400 & - & - & 990 & 877 & 200 & 0.5 & 3.25 & 75 \\
\hline & PC-60 & 350 & - & - & 1015 & 869 & 210 & 0.6 & - & 100 \\
\hline & PC-75 & 300 & - & - & 1050 & 810 & 225 & 0.75 & - & 140 \\
\hline \multirow{4}{*}{$30 \mathrm{FA}$} & FA-40 & 315 & 135 & - & 990 & 800 & 180 & 0.4 & 1.75 & 55 \\
\hline & FA-50 & 280 & 120 & - & 990 & 877 & 200 & 0.5 & 1.70 & 90 \\
\hline & FA-60 & 245 & 105 & - & 1015 & 869 & 210 & 0.6 & - & 125 \\
\hline & FA-75 & 210 & 90 & - & 1050 & 810 & 225 & 0.75 & - & 135 \\
\hline \multirow{4}{*}{ 50GGBS } & SL-40 & 225 & - & 225 & 990 & 800 & 180 & 0.4 & 1.65 & 40 \\
\hline & SL-50 & 200 & - & 200 & 990 & 877 & 200 & 0.5 & 1.60 & 50 \\
\hline & SL-60 & 175 & - & 175 & 1015 & 869 & 210 & 0.6 & - & 66 \\
\hline & SL-75 & 150 & - & 150 & 950 & 900 & 225 & 0.75 & - & 105 \\
\hline
\end{tabular}

CA - coarse aggregate, SA - fine aggregate, WC - water content, w/b - water/cementitious ratio, SP - plasticizers,

\section{Results and Discussion}

\subsection{Micro-climate variation at exposure sites}

Figures 1, 2 and 3 presents the average microclimatic conditions recorded at each exposure site through a 12month period. From Figure 1, it can be observed that the variability in $\mathrm{CO}_{2}$ concentration between the exposure sites is not significant but follow a defined pattern with the indoor site having higher $\mathrm{CO}_{2}$ concentration. However, slightly higher $\mathrm{CO}_{2}$ values are observed for the indoor exposure site in most months and this can be attributed to the enclosed nature and the lack of free flow of air. The indoor exposure site is a basement parking garage and would be influenced by $\mathrm{CO}_{2}$ from the exhaust fumes of cars. The outdoor exposed condition, unsheltered from rain and sun presented the least $\mathrm{CO}_{2}$ concentration. This can be ascribed to its height above ground level and distance from sources of $\mathrm{CO}_{2}$ pollution, since land use influences the $\mathrm{CO}_{2}$ concentration.

Generally, based on the $\mathrm{CO}_{2}$ variations presented in the figure and all other factors being equal, concrete samples exposed to the indoor condition should have the highest carbonation rates while concretes exposed outdoor and unsheltered should present the least carbonation rates. This is based on the fact that the rate of diffusion of $\mathrm{CO}_{2}$ into concrete increases with increase in $\mathrm{CO}_{2}$ concentration between the internal and external environment of the concrete. The implication of the $\mathrm{CO}_{2}$ variations for the durability performance and service life of concrete structures are that structural elements exposed to indoor conditions will be exposed to higher carbonation rates and should therefore be more carefully designed and constructed if its design service life in terms of the initiation limit state (ILS) is to be achieved.

From Figure 2, it can be seen that there exists a governing trend indicating a general decrease in the $\mathrm{RH}$ from May to September, followed by a steady decrease from October to February.

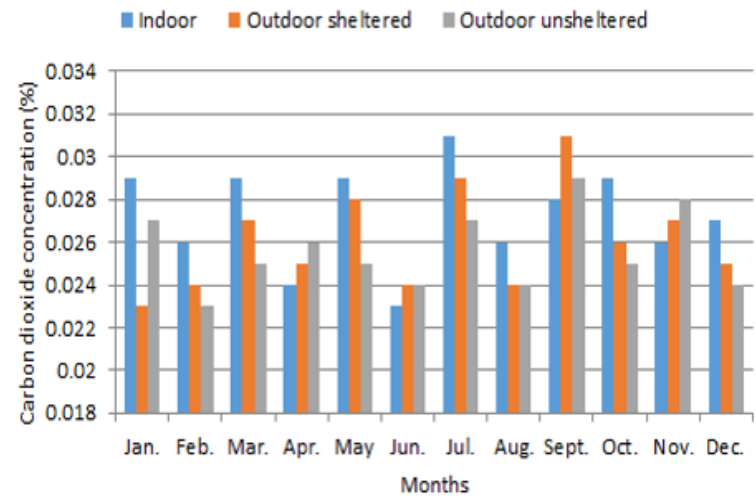

Fig. 1 Average monthly carbon dioxide variations for the exposure sites

The higher RH recorded in the raining period is related to precipitation associated with rainfall which is typically experienced from April to September.

Based on the RH results for the exposure sites and since the external RH influences the internal humidity of the concrete, it is evident that concrete samples exposed indoors had the lowest internal moisture content. Concretes exposed outdoors but sheltered from rain and sun, had moderate internal humidity judging from the exposure site RH values presented in Figure 2. While the moisture content for concrete samples exposed outdoor to rain and sun are high for most part of the year as the average monthly $\mathrm{RH}$ for this site is higher compared to the other sites.

Keeping other factors equal, the RH result presented shows that concrete cube samples exposed outdoor but sheltered from rain and sun will have the highest carbonation rates because this exposure site RH profile mostly lies in the zone for maximum carbonation rate $[16,17,18]$. The implication of the $\mathrm{RH}$ results for durability performance and service life of reinforced concrete elements is that structural elements exposed outdoor but sheltered will present the highest carbonation rate. Thus, such elements should be more carefully designed and constructed if its design service 
life in terms of the ILS is to be achieved. It is also evident that concrete elements exposed outdoor to rain and sun are at risk of corrosion due to the high $\mathrm{RH}$ as a results of the precipitation during raining months. Although the rate of carbonation may be very low for concrete elements exposed to the outdoor condition because of the low or high saturated pore structure which depend on the period of the year.

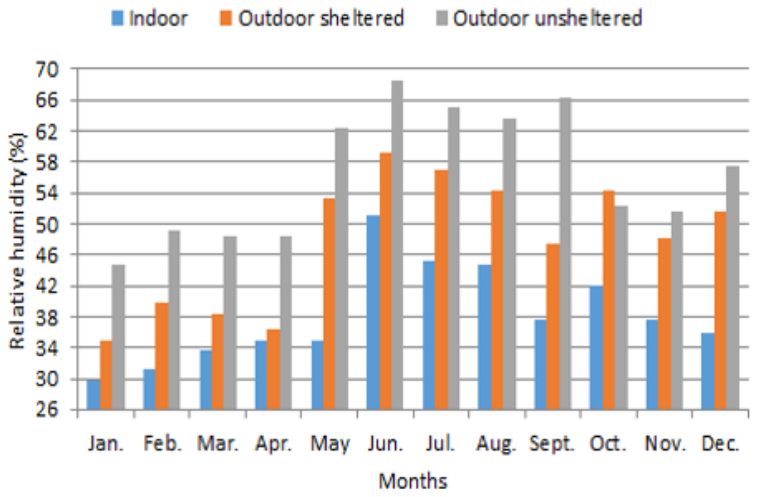

Fig. 2 Average monthly relative humidity variations for the exposure sites

Figure 3 shows the average monthly temperature variation within a span of one year for the three exposure sites. Generally, temperature decreases for all exposure sites from January to June and then increases from July to December. From the temperature measurements recorded for these sites, it is evident that the indoor exposure site experienced warmer conditions for most part of the year while it was cooler for the outdoor unsheltered. Although, the influence of temperature variations is not very significant for carbonation in concrete [19], results of the temperature variation shows that carbonation rates should be higher for concrete cube samples exposed indoors, while it may be similar for the other two exposure sites since their temperature profiles are similar.

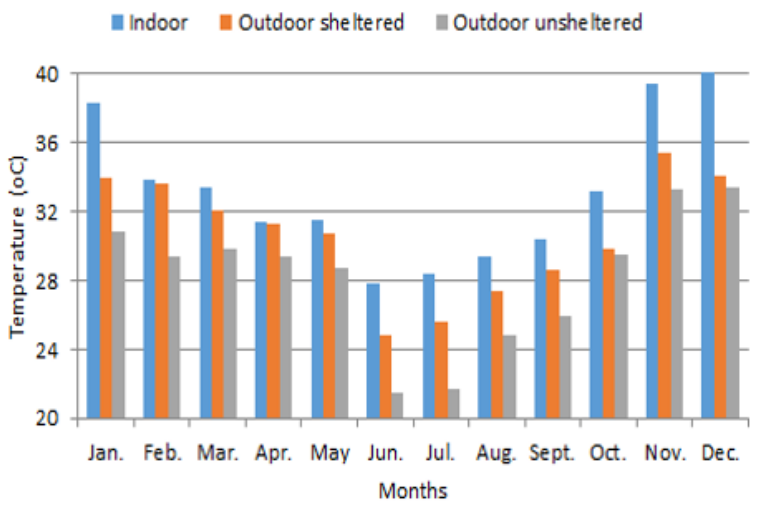

Fig. 3 Average monthly temperature variations for the exposure sites

\subsection{Natural carbonation}

Carbonation results obtained for the various concretes exposed to the natural inland environments are presented in Figure 4. As earlier mentioned, concrete samples were exposed to natural indoor and outdoor sites and monitored for carbonation at ages of $6,12,18$ and 24 months. Although the present study investigated the effects of the variability in microclimatic conditions on the rate of concrete carbonation, the influence of SCMs and curing periods are evident from the presented results. Concrete samples incorporating SCMs shows an increase in carbonation regardless of the exposure site conditions. While a longer initial moist curing duration generally resulted in a lower carbonation rate for all concretes type investigated. This is attributed to the fact that as curing increases hydration in concrete, the pore space in concrete reduces, particularly in the near surface zone. Additionally, curing influences the chemical properties of the concrete, for instance in unblended concrete it increases the $\mathrm{Ca}(\mathrm{OH})_{2}$ content of the concrete thereby improving its buffering effect against $\mathrm{CO}_{2}$ [20] However, curing reduces the $\mathrm{Ca}(\mathrm{OH})_{2}$ content in blended concretes but improves the concrete microstructure $[3,21]$. For example, in plain concretes, the carbonation rate decreased significantly with curing age within the first seven days. In the case of concrete containing SCMs, the carbonation rate continued to decrease even after 7 days of curing again pointing to the later hydration effect of these SCMs.

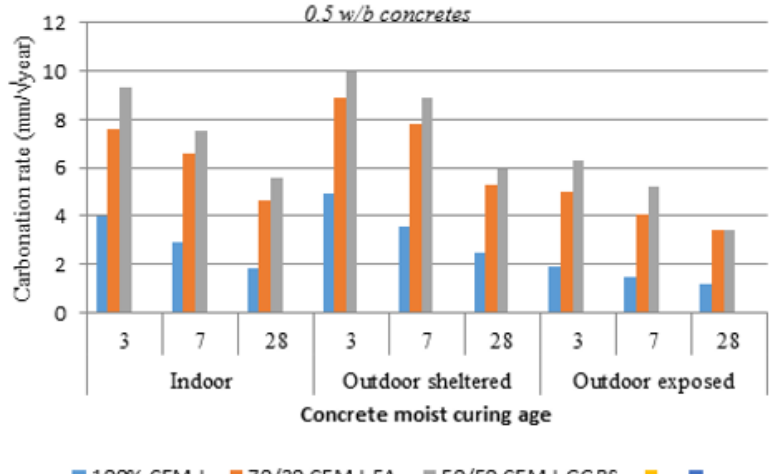

Fig. 4 Carbonation rate for concretes exposed to natural conditions

From the figure above, concrete cube samples exposed to the outdoor sheltered conditions presented the highest carbonation rate while the lowest carbonation rates were observed in the concrete cube samples at the outdoor exposed site. The wetting and drying period experienced by samples on the exposed site is probably the reason for the reduced carbonation rate, since both the outdoor sheltered and unsheltered exposure conditions have similar micro-climates in terms of $\mathrm{CO}_{2}$ content, $\mathrm{RH}$ and temperature as noted in Figures 1, 2 and 3 respectively. In addition, concrete cube samples exposed outdoor to rain and sun have higher internal humidity during the summer months from precipitation effects, thus reducing $\mathrm{CO}_{2}$ ingress during this period. Furthermore, these concretes had improved pore structures from rapid hydration effects as a result of its high internal moisture content during the summer months.

The micro-climatic factors known to influence the carbonation rate of concretes are the $\mathrm{CO}_{2}$ concentration, 
$\mathrm{RH}$ and temperature with the most important being $\mathrm{RH}$. The RH surrounding the concrete influences the concretes internal humidity which then affects the ingress of $\mathrm{CO}_{2}$. For instance, [22] noted an insignificant effect on concrete carbonation rate for samples with compressive strength less than or equal to $40 \mathrm{MPa}$ when the $\mathrm{CO}_{2}$ concentrations were varied between $7 \%$ and $18 \%$. While for concretes with strength higher than 40 $\mathrm{MPa}$, variation of a greater order of magnitude in $\mathrm{CO}_{2}$ concentration may be required to show any significant effect on the carbonation rate. The rate of carbonation in concrete is also weakly sensitive to temperature within the range $20-40{ }^{\circ} \mathrm{C}$ [23]. A similar observation regarding the insensitivity of temperature to the rate of carbonation in concrete was also noted by Loo et al., (1994) in their work.

\section{Conclusions}

The main aim for this paper was to investigate the influence of micro-climate variations on the carbonation rate of concretes in inland environments. Through the carbonation study, several conclusions can be drawn.

a. Increasing the duration of moist curing and reducing the amount of addition of supplementary cementing materials has a significant effect on decreasing the rate of carbonation in concrete.

b. Concrete samples in the outdoor exposed sites presented a lower rate of carbonation compared to the sheltered sites but higher than for the indoor sites.

c. Concretes element exposed outdoor are at risk of reinforcement corrosion when compared to the other two sites. This is as a result of the higher relative humidity and the cyclic wetting during rain period.

d. The micro-climate condition, especially the relative humidity, dictates the rate of carbonation of concrete in the inland environment. Thus, concrete samples in the outdoor sheltered sites presented the highest rate of carbonation. Although samples in this exposure site carbonate faster, the risk of reinforcement corrosion is likely to be low because the samples are protected from direct moisture effect.

This work is based on the research supported in part by the Tertiary Education Trust Fund (TETFund) of Nigeria. The first author also wishes to acknowledge the inspiration provided by Prof Yunus Ballim of the School of Civil \& Environmental Engineering, University of the Witwatersrand, Johannesburg, South Africa.

\section{References}

1. L. Bertolini, B. Elsener, P. Pedeferri, E. Redaelli, R.B. Polder. Corrosion of steel in concrete: prevention, diagnosis, repair: Wiley. com. (2013).

2. P.K. Mehta. Durability of concrete--fifty years of progress? ACI Special Publication, 126. (1991)

3. P. Mehta, P. Monteiro, P. Concrete: Structure, Properties, and Materials, Prentice-Hall, Englewood Cliffs, NJ, (1993).
4. L. Wu, G.X. Pu. Influencing factors of concrete carbonation and prediction model of carbonation depth. Technique of Seepage Control 8 (3), 10-12 (in Chinese with English abstract). (2002)

5. X.C. Zhou, X.C. Experimental study on the influence of mineral additive to the concrete air permeability. Shanxi Architecture 37 (10), 101-103 (in Chinese with English abstract). (2011)

6. Z.L. Meng, F. Zhu, H. Zhou, J.S. Qian. Carbonation and ways of preventing carbonation of high-volume fly ash concrete. Building Science Research of SiChuan27 (3), 50-54 (in Chinese with English abstract). (2001)

7. Y. Zhang, L.X. Jiang. A practical mathematical model of concrete carbonation depth based on the mechanism. Industrial Construction 28 (1), 16-19 (in Chinese with English abstract). (1998).

8. D.T Niu, Z.P. Dong, J.X. Pu. Random model of predicting the carbonated concrete depth. Industrial Construction 29 (9), 41-45 (in Chinese with English abstract). (1999).

9. A. Oner, S. Akyuz. 2007. An experimental study on optimum usage of GGBS for thecompressive strength of concrete. Cement and Concrete Composites 29, 505-514. (2007).

10. H.S. Shi, B.W. Xu, X.C. Zhou. Influence of mineral admixtures on compressive strength, gas permeability and carbonation of high performance concrete. Construction and Building Materials 23, 1980-1985. (2009)

11. R. Siddique, J. Klaus. Influence of metakaolin on the properties of mortar and concrete: a review. Applied Clay Science 43, 392-400. (2009)

12. E.H. Yang, Y.Z Yang, V.C. Li. Use of high volumes of fly ash to improve ECC mechanical properties and material greeniness. ACI Materials Journal 104 (6), 620-628. (2007).

13. D.M. Roy, P. Arjunan, M.R. Silsbee. Effect of silica fume, metakaolin, and low calcium fly ash on chemical resistance of concrete. Cement and Concrete Research31, 1809-1813. (2001).

14. H.W. Song, V. Saraswathy. 2006. Studies on the corrosion resistance of reinforced steel in concrete with ground granulated blast-furnace slag - an overview. Journal ofHazardous Materials B138, 226-233. (2006).

15. F.S. Fulton. Fulton's concrete technology, $9^{\text {th }}$ Edition (Gill Owens, ed.), Cement and concrete Institute, Midrand, Johannesburg, RSA. (2009).

16. G. Verbeck. (1958). Carbonation of hydrated Portland cement. Cement and Concrete, 17-36. (1958).

17. M. Richardson. Fundamentals of durable concrete, modern concrete technology: Published by Spon Press, London. (2002)

18. B.M. Fernandez, S. Simons, C. Hills, P. Carey. A review of accelerated carbonation technology in the treatment of cement-based materials and sequestration of $\mathrm{CO}_{2}$. Journal of Hazardous Materials, 112(3), 193-205. (2004) 
19. Da Silva, F., Helene, P., Castro-Borges, P., \& Liborio, J. (2009). Sources of variations when comparing concrete carbonation results. Journal of materials in civil engineering, 21(7), 333-342. (2009).

20. Ballim, Y. (1994). Curing and the durability of concrete. PhD Thesis, University of the Witwatersrand.

21. V.G. Papadakis. Effect of supplementary cementing materials on concrete resistance against carbonation and chloride ingress. Cement and Concrete Research, 30(2), 291-299. (2000)

22. Y. Loo, M. Chin, C. Tam, K. Ong. (1994). A carbonation prediction model for accelerated carbonation testing of concrete. Magazine of Concrete Research, 46(168), 191-200. (1994).

23. V.G. Papadakis, C.G. Vayenas, M.N. Fardis. Fundamental modelling and experimental investigation of concrete carbonation. American Concrete Institute Materials Journal. 88(4): 363373. (1991). 